\title{
Production of Cytolethal Distending Toxin and Other Virulence Characteristics of Escherichia coli Strains of Serogroup 086
}

\author{
Ângela Cristina Rodrigues Ghilardi/+ , Tânia Aparecida Tardelli Gomes*, \\ Luiz Rachid Trabulsi**
}

\author{
Seção de Bacteriologia, Instituto Adolfo Lutz, Av. Dr Arnaldo 351, $9^{\circ}$ andar, 01246-902 São Paulo, SP, Brasil \\ *Departamento de Microbiologia, Universidade Federal de São Paulo, São Paulo, SP, Brasil \\ **Laboratório Especial de Microbiologia, Instituto Butantã, São Paulo, SP, Brasil
}

Genetic and phenotypic virulence markers of different categories of diarrhoeagenic Escherichia coli were investigated in 106 strains of enteropathogenic E. coli (EPEC) serogroup O86. The most frequent serotype found was O86:H34 (86\%). Strains of this serotype and the non motile ones behaved as EPEC i.e., carried eae, bfpA and EAF DNA sequences and presented localised adherence to HeLa cells. Serotypes O86:H2, O86:H6, O86:H10, O86:H18, O86:H27 and O86:H non determined, belonged to other categories. The majority of the strains of serotype O86:H34 and non motile strains produced cytolethaldistending toxin (CDT). The ribotyping analysis showed a correlation among ribotypes, virulence markers and serotypes, thus suggesting that CDT production might be a property associated with a universal clone represented by the O86:H34 serotype.

Key words: enteropathogenic Escherichia coli - serogroup O86 - cytolethal distending toxin - virulence markers diarrhoea

Escherichia coli strains associated with diarrhoeal disease were first classified on the basis of their somatic (O) and flagelar (H) antigens. In 1987, the World Health Organization (WHO) recognized as enteropathogenic $E$. coli (EPEC) the following serogroups: O26, O55, O86, O111, O114, O119, O125, O126, O127, O128, O142 and O158 (WHO 1987). With the introduction of tissue culture assays and DNA probes to study the virulence of $E$. coli strains associated with diarrhoea, it has been possible to demonstrate the existence of at least six established or putative categories of diarrhoeagenic E. coli: enteropathogenic E. coli (EPEC), enterohemorragic E. coli (EHEC), enterotoxigenic $E$. coli (ETEC), enteroinvasive $E$. coli (EIEC), enteroaggregative E. coli (EAEC) and difuselly adhering $E$. coli (DAEC). Recently, a new category termed atypical EPEC has been proposed (Nataro \& Kaper 1998). In addition to the defin-

This work was supported by grants 62.0236/92-2 (PADCT/CNPq) and 96/4148-5 (Fapesp) awarded to L $\mathrm{R}$ Trabulsi.

${ }^{+}$Corresponding author. Fax: $+55-11-3085$ 3505. E-mail: thagui@attglobal.net

Received 28 October 2000

Accepted 22 February 2001 ing characteristics, strains of some serogroups might present other virulence properties that could contribute to their pathogenesis.

Studies carried out by several authors in the last few years, have shown that the EPEC serogroups are very heterogeneous. In general, they include more than one of the seven diarrhoeagenic E. coli categories (with the exception of EIEC) and each category have specific $\mathrm{H}$ antigens, corresponding to defined $E$. coli serotypes (Campos et al. 1994, Rodrigues et al. 1996, Gonçalves et al. 1997, Valle et al. 1997).

The first $E$. coli strain of serogroup O86 ( $E$. coli E990) was identified by Taylor and Charter (1952) as the cause of an outbreak of acute diarrhoea in children committed to day care in London. Since then, strains of this serogroup, mainly of serotype $\mathrm{O} 86: \mathrm{H} 34$, have been isolated in outbreaks and sporadic cases of diarrhoea in many parts of the world (Toledo et al. 1983, Gomes et al. 1989, Scotland et al. 1996, Cravioto et al. 1996).

Cytolethal Distending Toxin (CDT) is a heatlabile factor which induces a progressive distension and death of various cell lines cultivated in vitro. CDT production has been detected in the supernatants of some E. coli, Shigella spp., Campylobacter spp., Haemophilus ducrey and Actinobacillus actinomycetemcomitans strains (Johnson \& Lior 1987, 1988a,b, Cope et al. 1997, Mayer et al. 1999). However, so far, CDT produc- 
tion has not been associated to any particular category of diarrhoeagenic $E$. coli, except for a few strains of EPEC serogroups including the O86:H34 serotype (Johnson \& Lior 1988a, Guth et al. 1994).

The purpose of this study was to determine the virulence characteristics of serogroup O86 strains isolated in Brazil and in other countries and to investigate the relationship between serotypes and ribotypes in this serogroup.

\section{MATERIALS AND METHODS}

Bacterial strains and serotyping - The study employed 90 E. coli strains which were isolated from faeces of children with diarrhoea at Instituto Adolfo Lutz, São Paulo, Brazil, between 1977 and 1991. For comparative purposes we included 14 E. coli strains from other countries, kindly provided by Dr Fleming Schultz, from Department of Gastrointestinal Infections, Denmark and E. coli strains from Chile and Centers for Disease Control (CDC), Atlanta, Ga, included in Dr Luiz R Trabulsi's collection.

The original strains kept at room temperature were grown in Triptic Soy Broth (TSB) and streaked out onto nutrient agar for serogroup confirmation and determination of $\mathrm{H}$ antigens (Edwards 1986).

Adherence to HeLa cells - Adherence was assayed in the presence of $1 \% \mathrm{D}$-mannose (Cravioto et al. 1979). Briefly monolayers were examined after $3 \mathrm{~h}$ of incubation, and poorly adherent and non-adherent strains were submitted to a period of assay of 6 h E. coli strains E2348/69, O42, and C1845 were used as control of localized, aggregative and diffuse adherence, respectively (Valle et al. 1997).

Hybridisation with DNA probes - All strains were submitted to colony hybridisation assays (Maas 1983), using specific DNA probes for different categories of diarrhoeagenic $E$. coli: eae $(E$. coli attaching and effacing gene encoding intimin), EAF (EPEC adherence factor plasmid), $b f p A$ (bundle forming pilus), $\mathrm{daaC}$ (associated with diffuse adherence), EAEC (associated with aggregative adherence), INV (E. coli invasiveness), Stx-1 and 2 (Shiga-toxin types 1 and 2), LT-I and II (heat-labile enterotoxin types I and II), ST-I p and h (heat-stable enterotoxin type I, from $E$. coli of porcine and human origin, respectively) (Rodrigues et al. 1996). The CDT probe used was the 1,375 bp- Acc I fragment of pCVD448 derived from E. coli E6468/62 (O86:H34) (Scott \& Kaper 1994). Probes were isotopically labelled and used in colony hybridisation assays as described elsewhere (Rigby et al. 1977).

Citotoxicity assays - CDT production was investigated in CDT probe positive and negative strains by testing in HeLa cells as described previouly (Johnson \& Lior 1988a). Briefly, strains were grown statically in $2 \mathrm{ml}$ of Brain Heart Infusion broth (BHI) at $37^{\circ} \mathrm{C}$, for $48 \mathrm{~h}$. The cells were pelleted and the supernatant fraction was retained and filtered. To prepare the sonicate, the pellet was resuspended in $1 \mathrm{ml}$ of Eagle's Minimal Essential Medium, modified with Earle's salts (MEM) and the suspension was sonicated as described by Pickett et al. (1994). Supernatants and sonicates were diluted 1:4 and 1:10 respectively for the assays and morphological changes were monitored every $24 \mathrm{~h}$ for 5 days. Strain 0741-4 (O86:H34) (Guth et al. 1994) was used as positive control. Sonicates presenting activity similar to that of the CDT control were submitted to neutralisation assays with rabbit anti-CDT serum, kindly provided by $\mathrm{Dr} \mathrm{H}$ Lior. Equal volumes of sonicate diluted 1:5 and antisera (imunne and non-imunne) diluted 1:128 in MEM, were mixed and incubated at $37^{\circ} \mathrm{C}$. After $2 \mathrm{~h}$ the mixture was submitted to citotoxicity assays.

Ribotyping - The genomic DNA of 33 strains carrying different $\mathrm{H}$ antigens and virulence markers, was extracted by the method described by Brenner et al. (1982). Approximately $2 \mu \mathrm{g}$ of DNA were digested with $B g l I$ (Sigma) and eletrophoresed with a marker (Haemophilus aegyptius strain, 320/ 86), digested with EcoRI (Dalla-Costa et al. 1998). The DNA was transferred onto a nylon membrane (Magnagraph, USA) in a vacuum blotting system (Vacum Gene XL, Pharmacia), according to the manufacture's instructions. A cDNA probe prepared by reverse transcriptation of $16 \mathrm{~S}$ plus $23 \mathrm{~S}$ rRNA (Boerhinger, Germany) and labelled using the digoxigenin DNA labelling and detection Kit (Boerheinger) as described (Popovic et al. 1993).

\section{RESULTS}

The 106 strains tested, belonged to six distinct serotypes. Seven strains were non motile $(\mathrm{O} 86: \mathrm{H})$ and the $\mathrm{H}$ antigen of one strain could not be determined (O86:H?) (Table I).

The data in Fig. 1 showed that O86:H34 was the predominant serotype in São Paulo, between 1977 and 1982.

None of the strains studied reacted with the probes for daaC, INV, LT-I and II, ST-Ip and h, and Stx 1 and 2. Table II shows the results obtained with the other probes and the adherence patterns presented by different strains. Presence of EPEC sequences (eae, EAF and $b f p A$ ) was detected in most strains of serotype O86:H34 (72 of $78 \mathrm{Bra}-$ zilian strains and all 6 strains of other countries). Moreover, these probe positive strains produced localised adherence (LA) in HeLa cells. Four of 7 O86:H- strains had these same properties. All 10 
TABLE I

Sources and flagellar antigens (H types) of 106 Escherichia coli strains

\begin{tabular}{|c|c|c|c|c|c|c|c|c|c|c|}
\hline \multirow[t]{2}{*}{ Origin } & \multirow[t]{2}{*}{ Period of isolation } & \multirow[t]{2}{*}{ No. of strains } & \multicolumn{8}{|c|}{ No. of the $\mathrm{H}$ type } \\
\hline & & & $\mathrm{H}$ ? & $\mathrm{H}-$ & $\mathrm{H} 2$ & H6 & $\mathrm{H} 10$ & $\mathrm{H} 18$ & $\mathrm{H} 27$ & H34 \\
\hline $\begin{array}{l}\text { São Paulo } \\
\text { (Brazil) }\end{array}$ & $1977-1991$ & 90 & 1 & 7 & - & 1 & 2 & 1 & - & 78 \\
\hline Denmark & 1966-1989 & 9 & - & - & 5 & - & - & 1 & 1 & 2 \\
\hline Guine Bissau & 1990 & 3 & - & - & 2 & - & - & - & - & 1 \\
\hline India & 1986 & 2 & - & - & 1 & - & - & - & - & 1 \\
\hline $\begin{array}{l}\text { CDC } \\
\text { (Atlanta) }\end{array}$ & Unknow & 1 & - & - & - & - & - & - & - & 1 \\
\hline Chile & Unknow & 1 & - & - & - & - & - & - & - & 1 \\
\hline Total & & 106 & 1 & 7 & 8 & 1 & 2 & 2 & 1 & 84 \\
\hline
\end{tabular}

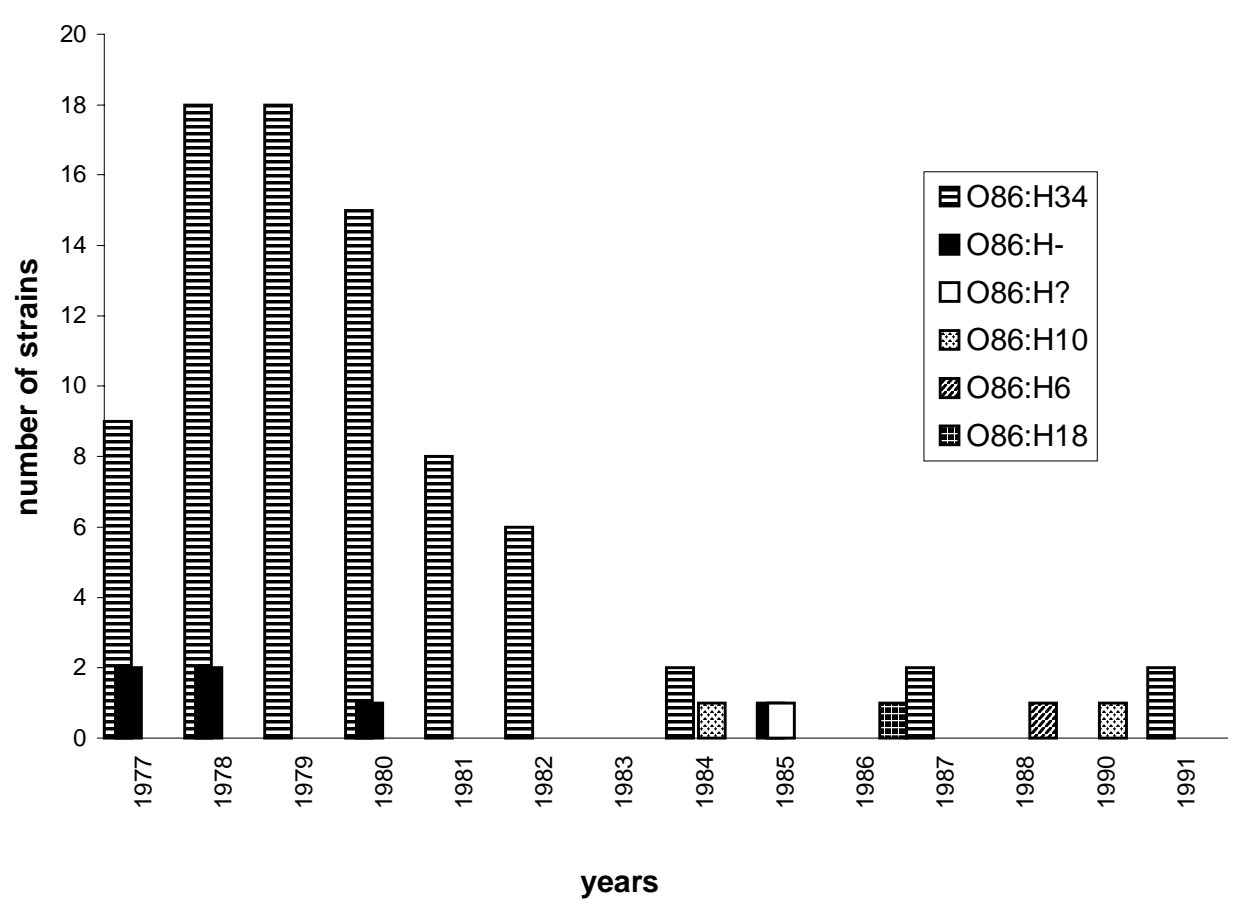

Fig. 1: distribution of Escherichia coli strains belonging to six serotypes of Enteropathogenic E. coli serogroup O86, São Paulo, 1977-1991.

strains of serotypes O86:H18 and O86:H2 produced the aggregative adherence (AA). Strains of the remaining serotypes were eae positive; (O86:H6, O86:H?) or lacked any virulence property searched for; (O86:H27, O86:H10).

Most of the strains (79 of 85) of serotypes O86:H34 and O86:H- isolated in São Paulo and all strains of serotype O86:H34 from other countries had the CDT sequence and produced a progressive distention on HeLa cells after $48 \mathrm{~h}$ of incubation. The distending activity of the sonicates was completely neutralized by rabbit antiserum to CDT.
Among the E. coli $\mathrm{O} 86$ strains isolated in São Paulo we observed five ribotypes (RT) named RTA to RT-E. The O86:H34 and the virulent O86:Hstrains, including the prototype strain E990 (O86:H-), belonged to RT-A. The O86:H- with no virulence sequences belonged to RT-B. The serotypes O86:H10, O86:H18 and O86:H6 belonged to RT-C, RT-D and RT-E, respectively. The O86 E. coli strains isolated in other countries belonged to four ribotypes, RT-I to RT-IV. The O86:H2, O86:H18, O86:H34 and O86:H27 strains belonged to RT-I, RT-II, RT-III and RT-IV, respectively (Fig. 2). 
TABLE II

Virulence properties of 106 Escherichia coli O86 strains

\begin{tabular}{|c|c|c|c|c|}
\hline Serotype & Origin & Virulence DNA sequences & CDT Probe & Adherence patterns \\
\hline & & $e a e, b f p A$, EAF (72) & $+(68)$ & $\mathrm{LA}^{a}(72)$ \\
\hline \multirow[t]{2}{*}{ H34 (78) } & Brazil & eae (4) & $+(4)$ & $I^{b}(4)$ \\
\hline & & $b f p A$, EAF (2) & $+(2)$ & $\mathrm{LA}^{a}(2)$ \\
\hline \multirow[t]{2}{*}{ H34 (6) } & Denmark, India, & & & \\
\hline & G. Bissau, Chile, CDC & $e a e, b f p A$, EAF (6) & $+(6)$ & $\mathrm{LA}^{a}(6)$ \\
\hline H27 (1) & Denmark & None (1) & - & NA (1) \\
\hline H18 (1) & Brazil & EAEC (1) & - & $\mathrm{AA}^{a}(1)$ \\
\hline H18 (1) & Denmark & EAEC (1) & - & $\mathrm{AA}^{a}(1)$ \\
\hline H10 (2) & Brazil & None (2) & - & NA (2) \\
\hline H6 (1) & Brazil & eae (1) & - & NA (1) \\
\hline \multirow[t]{2}{*}{$\mathrm{H} 2(8)$} & Denmark, G. Bissau, & EAEC (6) & - & $\mathrm{AA}^{b}(6)$ \\
\hline & India & None (2) & - & $\mathrm{AA}^{b}(2)$ \\
\hline \multirow[t]{3}{*}{$\mathrm{H}-(7)$} & Brazil & $e a e, b f p A$, EAF (4) & $+(4)$ & $\mathrm{LA}^{a}(4)$ \\
\hline & & eae (1) & $+(1)$ & NA (1) \\
\hline & & None (2) & - & NA (2) \\
\hline $\mathrm{H} ?(1)$ & Brazil & eae (1) & - & NA (1) \\
\hline E990 (O86:H-) & Prototype strain & eae (1) & $+(1)$ & $\mathrm{I}^{b}(1)$ \\
\hline
\end{tabular}

$a$ : adhesion test of $3 \mathrm{~h} ; b$ : adhesion test of $6 \mathrm{~h}$; LA: localized adherence pattern; AA: aggregative adherence pattern; I: indefinite adherence pattern; NA: not adherent; ( ) no. of strains

a

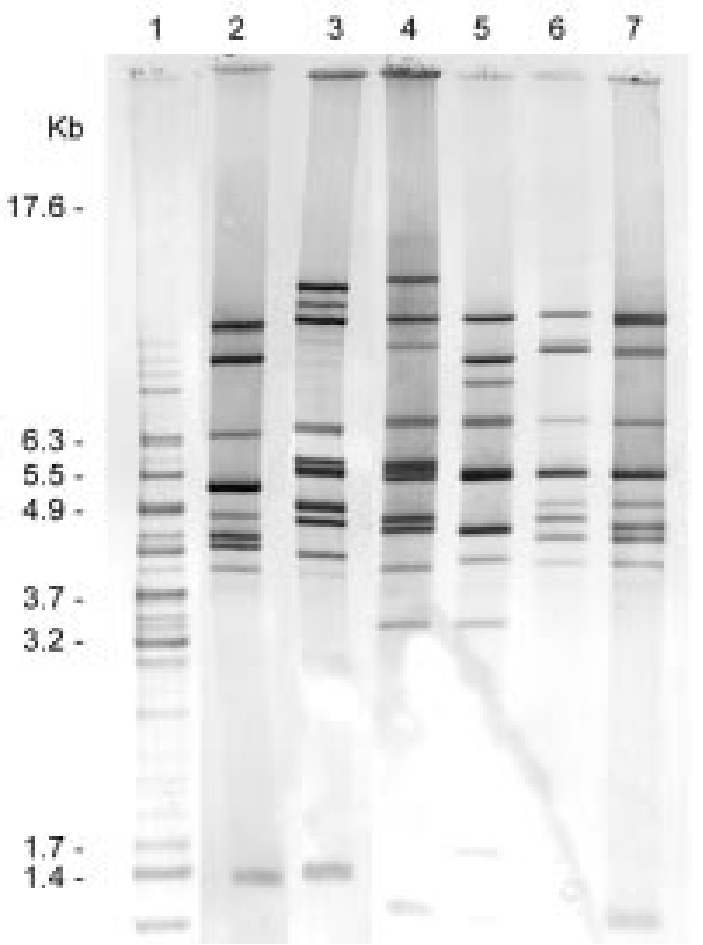

b

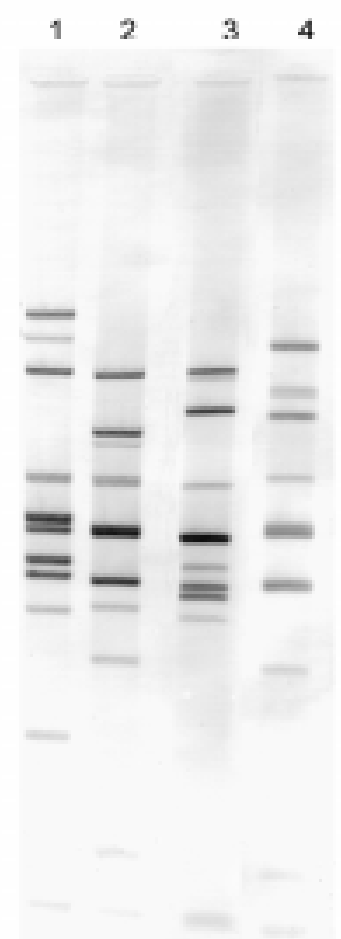

Fig. 2: ribotypes and serotypes of Escherichia coli strains, serogroup O86. a: isolated in Brazil. Slot 1-Marker; Slot 2-RT-A, O86:H34 and O86:H-(with virulence sequences); Slot 3-RT-B, O86:H-(with no virulence sequences); Slot 4-RT-C, O86:H10; Slot 5-RT-D, O86:H18; Slot 6-RT-E, O86:H6; Slot 7-RT-A, E990, O86:H-(with virulence sequence); b: isolated in other countries Slot 1-RT-I, O86:H2; Slot 2-RT-II, O86:H18; Slot 3-RT-III, O86:H34; Slot 4-RT-IV, O86:H27 


\section{DISCUSSION}

In this study, we examined a diverse collection of $E$. coli 086 strains isolated from human diarrhoea, in different countries. We observed that the most frequent serotype of serogroup O86, found in São Paulo (O86:H34) (Toledo et al. 1983, Gomes et al. 1989) is not the most frequent in other countries (Scotland et al. 1996, Giamanco et al. 1996). Therefore, geographic variation in the predominance of the EPEC serotypes may occur. The serotype O86:H34 was predominant in São Paulo between 1977 and 1991 and since then, it has been isolated no more frequently than the other less common serotypes of this serogroup, found in São Paulo. This kind of distribution suggested the ocurrence of an outbreak, which started before or at the beginning of 1977 and disappeared in 1982, or that this serotype was endemic until 1990, when its frequency started to fall (Fig. 1).

Typical EPEC strains, i.e., strains carrying EAF, $b f p A$, eae and presenting LA in the $3 \mathrm{~h}$ adherence assay, were found in $82(77.4 \%)$ of the strains studied, which were comprised in the serotypes O86:H34 and O86:H-. The strains of serotypes O86:H18 and 6 of 8 O86:H2 strains were categorised as EAEC, since they presented the aggregative adherence pattern and hibridised with the EAEC probe. Lack of hybridisation with the EAF probe in four O86:H34 strains and with the EAEC probe in two O86: $\mathrm{H} 2$ strains, is probably attributed to genetic alterations that often occur in E. coli stored for long periods (Rodrigues et al. 1996, Gonçalves et al. 1997). Strains of serotypes O86:H6 and O86:H? showed the characteristics of atypical EPEC (i.e., eae only). No sequences associated with intestinal infections were found in the strains of serotypes O86:H27 and O86:H10 (Table II). The data described above, agreed with the findings reported by other authors (Scotland et al. 1996, Cravioto et al. 1996, Giamanco et al. 1996).

Of particular interest in this study was the demonstration that besides having all the virulence characteristics of typical EPEC, most of the strains of serotypes O86:H34 and the virulent O86:Hstrains produced CDT, and it could act as an additional virulence factor of diarrhoea. Although O86:H34 and O86:H- may be considered as distinct serotypes, it is likely that the virulent $\mathrm{H}$ - strains were derived from O86:H34 strains, because they have identical virulence characteristics and were isolated in the same period of time (Fig. 1, Table II). Until now, among the EPEC serotypes, frequent production of CDT seemed to be an exclusive characteristic of the serotype O86:H34. In fact, in a survey of CDT production by EPEC serogroups O55, O86, O119, O126, O127 and O142, Guth et al. (1994) found that only O86:H34 strains produced CDT. CDT producing strains have been reported among E. coli strains isolated in Canada and India, although in one of these studies serotyping was not performed (Bouzari et al. 1990) and in the other one, a single CDT positive strain of serotype O86:H34 was found (Johnson \& Lior 1988a). A significant percentage of CDT producing strains belonging to the same serotype has not been reported so far. The role of CDT in the pathogenicity of E. coli strains has not been studied. It is possible that CDT production alone, has no implication for pathogenesis but its production by $E$. coli strains in combination with other virulence factors, such as the ability to adhere to the intestinal mucosa, may be significant. Albert et al. (1996) did not find an important association between CDT positive $E$. coli strains and diarrhoea but it has been shown in a recent study that this toxin has diarrhoeagenic properties in an animal model (Okuda et al. 1997).

We found an association between $\mathrm{O}: \mathrm{H}$ serotypes and ribotypes among the studied strains. This relationship allowed the identification of non motile strains $(\mathrm{O} 86: \mathrm{H}-)$ by comparing their fingerprints with those of the motile strains, i.e., RT-B (O86:H-) and RT-I (O86:H2), the prototype strain E990 (O86:H-), and RT-A and RT-III (O86:H34) (Fig. 2). This finding confirmed that this kind of flagellar variation occurred with relatively high frequency, a phenomenon that has also been observed in other EPEC serogroups (Rodrigues et al. 1996, Gonçalves et al. 1997). Despite of that, the ribotype presented by the O86:H34 strains isolated in Brazil (RT-A) was the same of the O86:H34 strains isolated in other countries (RT- III) (Fig. 2 ), suggesting that CDT production could be associated with a clone distributed all over the world represented by strains belonging to the serotype O86:H34.

\section{ACKNOWLEDGEMENTS}

To James B Kaper (University of Maryland) for providing us with the CDT probe and Dr Fleming Schultz (Departament of Gastrointestinal Infections, Denmark) who kindly sent us the strains from other countries.

\section{REFERENCES}

Albert MJ, Faruque MS, Faruque SGA, Bettelheim AK, Neogi BKP, Bhuiyan AN, Kaper J 1996. Controlled study of cytolethal distending toxin producing Escherichia coli infections in Bangladesh children. $J$ Clin Microb 34: 717-719.

Bouzari S, Varghese A 1990. Cytolethal distending toxin (CDT) production by enteropathogenic Escherichia coli (EPEC). FEMS Microbiol Lett 71: 193-198.

Brenner DJ, Mc Whorter AC, Knutson JKL, Steigerwalt AD 1982. Escherichia vulneris a new specie of 
Enterobacteriacea associated with human wounds. J Clin Microbiol 15: 1133-1140.

Campos LC, Whittam TS, Gomes TAT, Andrade JRC, Trabulsi LR 1994. Escherichia coli serogroup O111 includes several clones of diarrheagenic strains with different virulence properties. Infect Immun 62: 3282-3288.

Cope LD, Lumbley S, Latimer JL, Klesney-Tait J, Stevens MK, Johnson LS, Purven M, Munson RS, Hansen EJ 1997. A diffusible cytotoxin of Haemophilus ducrey. Proc Natl Acad Sci USA 94: 4056-4061.

Cravioto A, Gross RJ, Scotland SM, Rowe B 1979. An adhesive factor found in strains of $E$. coli belonging to the traditional infantile enteropathogenic. Current Microbiol 3: 95-99.

Cravioto A, Molina J, Manjarrez A, Eslava C 1996. The Mexican experience. Rev Microbiol 27 (suppl.1): 2124.

Dalla-Costa LM, Irino K, Rodrigues J, Rivera ING, Trabulsi LR 1998. Characterization of diarrheagenic Escherichia coli clones by ribotyping and ERICPCR. J Med Microbiol 47: 227-234.

Edwards WH 1986. Identification of Enterobacteriaceae, 4 th ed., Elsevier Science, New York.

Giamanco A, Maggio M, Giamanco G, Morelli R, Minelli F, Scheutz F, Caprioli A 1996. Characteristics of Escherichia coli strains belonging to enteropathogenic $E$. coli serogroups isolated in Italy from children with diarrhea. J Clin Microbiol 34: 689694.

Gomes TAT, Vieira MAM, Wachsmuth IK, Blake PA, Trabulsi LR 1989. Serotype-Specific Prevalence of $E$. coli strains with EPEC adherence factor genes in infants with and without diahorrea in São Paulo, Brazil. J Infect Dis 160: 131-135.

Gonçalves AG, Campos LC, Gomes TAT, Rodrigues J, Sperandio V, Whittam TS, Trabulsi LR 1997. Virulence properties and clonal structures of strains of Escherichia coli $\mathrm{O} 119$ serotypes. Infect Immun 65: 2034-2040.

Guth BEC, Giraldi R, Gomes TAT, Marques LRM 1994. Survey of cytotoxin production among Escherichia coli strains characterized as enteropathogenic (EPEC) by serotyping and presence of EPEC adherence factor (EAF sequence). Can J Microb 40: 341344.

Johnson WN, Lior H 1987. Production of Shiga toxin and a cytolethal distending toxin (CDT) by serogroups of Shigella spp. FEMS Microbiol Lett 48: 235-238.

Johnson WN, Lior H 1988a. A new heat labile cytolethal distending toxin (CDT) produced by Escherichia coli isolated from clinical material. Microb Pathog 4: 103-113.

Johnson WN, Lior H 1988b. A new heat labile cytolethal distending toxin (CDT) produced by Campylobacter spp. Microb Pathog 4: 115-116.

Maas R 1983. An improved colony hibridization method with significantly increased sensitivity for detection of single genes. Plasmid 10: 296-298.

Mayer MPA, Bueno LC, Hanse EJ, DiRienzo JM 1999. Identification of a cytolethal distending toxin gene locus and features of virulence-associated region in Actinobacillus actinomycetemcomitans. Infect Immun 67: 1227-1237.

Nataro JP, Kaper JB 1998. Diarrheagenic E. coli. Clin Microbiol Rev 11: 142-201.

Okuda J, Fukumoto M, Takeda Y, Nishibuchi M 1997. Examination of diarrheagenicity of cytolethal distending toxin: suckling mouse response to the products of the $c d t \mathrm{ABC}$ genes of Shigella dysenteriae. Infect Immun 65: 428-433.

Pickett CL, Cotlle DL, Pesci EC, Bikah G 1994. Cloning, sequencing and expression of the Escherichia coli cytolethal distending toxin genes. Infect Immun 62: 1046-1051.

Popovic T, Bopp CA, Olsvik O, Kiehlbauch A 1993. Ribotyping in molecular epidemiology. In $\mathrm{DH}$ Persing, TF Smith, FC Tenover, TJ White (eds), Diagnostic Molecular Microbiology Principles and Applications, American Society for Microbiology Washington D.C, p. 573-583.

Rigby PWJ, Diechmnan M, Rhodes C, Berg P 1977. Labelling deoxyribonucleic acid to high specific activity in vitro by nick translation with DNA polymerase. J Mol Biol 114: 237-251.

Rodrigues J, Scaletsky ICA, Campos LC, Gomes TAT, Whittam TS, Trabulsi LR 1996. Clonal structure and virulence factors in strains of Escherichia coli of the classic serogroup O55. Infect Immun 64: 2680-2686.

Scotland SM, Smith HR, Cheasty T, Said B, Willshaw GA, Stokes N, Rowe B 1996. Use of gene probe and adhesion test to characterize Escherichia coli belonging to enteropathogenic serogroups isolated in United Kingdom. J Med Microbiol 44: 438-443.

Scott D, Kaper JB 1994. Cloning and sequencing of genes encoding Escherichia coli cytolethal distending toxin. Infect Immun 62: 244-251.

Taylor J, Charter RE 1952. The isolation of serological types of Bacterium coli in two residential nurseries and their isolation to infantile gastroenteritis. $J$ Path Bacteriol 64: 715-728.

Toledo MRF, Alvariza MCB, Murahovsky J, Ramos SRTS, Trabulsi LR 1983. Enteropathogenic Escherichia coli serotypes and endemic diarrhea in infants. Infect Imunn 39: 586-589.

Valle GRF, Gomes TAT, Irino K, Trabulsi LR 1997. The traditional enteropathogenic Escherichia coli (EPEC) serogroup O125 comprises serotypes which are mainly associated with the category of enteroaggregative E. coli. FEMS Microbiol Lett 152: 95-100.

WHO-World Health Organization 1987. Programme for control of diarrheal diseases (CDD/83.3 Rev1). In Manual for Laboratory Investigations of Acute Enteric Infections, WHO, Geneva, p. 27. 